body of a small young shark. It was about eighteen inches long. I secured this as evidence. This locality is about 170 miles from the mouth of the river.

During the six months we were in the country, the bed of the river, which varies from 50 to 800 yards in width, was almost dry, with the exception of deep pools at intervals connected with each other by a narrow stream, often very shallow, running under the high banks. In the summer time the river is deeply flooded, the water rising ten to twenty feet (as shown by drift wood in trees) above the banks, in many places from forty to fifty feet high. The force of the flood might at its height prevent fish going up, but they could easily ascend in the intermediate season. In some cases the fish must have lived months in the upper waters, for portions of the Margaret, at least, are absolutely dry in the winter season, May to November usually.

I am not aware that such a circumstance has ever been noted before. If not, the fact is sufficientiy interesting in itself. It is also important from a geological point of view, as showing that some caution must be observed in the classification of strata as freshwater or marine on the evidence of fish alone. No doubt many of these remains are embedded in the river detritus, and if discovered at some future time when the physical geology of the country has altered, might lead to the conclusion that these deposits were of marine origin.

EDWARD F. HARDMAN,

H.M. Geological Survey, Government Geologist

Perth, Western Australia, January 28

\section{The Zodiacal Light}

ONE of the members of the staff of this establishment, Mr. E. G. Constable, ob̀served a brilliant appearance of the zodiacal light at about $7 \mathrm{p} . \mathrm{m}$. on the evening of Wednesday the 5 th inst., the cone of light being exceedingly well defined. The phenomenon was not visible long, having completely disappeared by $7.20 \mathrm{p} . \mathrm{m}$.

Kew Observatory, Richmond, Surrey, March 7

\section{THE AXIOMS OF GEOMETRY}

SIN

$\mathrm{NCE}$ the time when Riemann and Helmholtz began their investigations on the axioms of geometry so much has been written on this subject in learned papers and in a more or less popular form that it might have appeared superfluous again to call the attention of writers on, and teachers of, elementary geometry to it, had it not been for the publication a year or two ago of a new edition of the first six books of Euclid's "Elements," with annotations and notes, by Prof. Casey. I hope the eminent author of this in many respects excellent book will excuse me for criticising some points in it, and making them the opportunity for again returning to the question about the axioms in geometry.

The points I object to besides his treatment of Book V., of which I may possibly say a few words on another occasion, is contained in Note B at the end of the book. Here Prof. Casey gives Legendre's and Hamilton's proofs of I. 32, that the sum of the interior angles of any triangle is equal to two right angles, implying, of course, that he considers these proofs valid, proofs which are independent of the theory of parallels. The theorem in question depends in Euclid upon Axiom XII., and all depends upon the question whether this axiom is necessary. For the two propositions in this axiom and in Theorem I. 32 stand in such a relation that either is a consequence of the other. Hence if I. 32 can be proved independently, the Axiom XII. changes into a theorem. But the investigations above referred to show that it is this axiom which tells us what kind of a surface the plane really is, and that until this axiom is introduced all propositions apply equally well to the spherical and to the plane surface.

I select for discussion the "quaternion proof" given by Sir William Hamilton, this being the easiest of the two. But that by Legendre can be treated in exactly the same way.

Hamilton's proof consists in the following :--
One side $\mathrm{A} B$ of the triangle $\mathrm{A} \mathrm{B} \mathrm{C}$ is turned about the point $B$ till it lies in the continuation of $B C$; next, the line $\mathrm{B} C$ is made to slide along $\mathrm{B} C$ till $\mathrm{B}$ comes to $\mathrm{C}$, and is then turned about $\mathrm{C}$ till it comes to lie in the continuation of A C. It is now again made to slide along $\mathrm{C} \mathrm{A}$ till the point $B$ comes to $A$, and is turned about $A$ till it lies in the line A B. Hence it follows, since rotation is independent of translation, that the line has performed a whole revolution, that is, it has been turned tbrough four right angles. But it has also described in succession the three exterior angles of the triangle, hence these are together equal to four right angles, and from this follows at once that the interior angles are equal to two right angles.

To show how erroneous this reasoning is-in spite of Sir William Hamilton and in spite of quaternions-I need only point out that it holds exactly in the same manner for a triangle on the surface of the sphere, from which it would follow that the sum of the angles in a spherical triangle equals two right angles, whilst this sum is known to be always greater than two right angles. The proof depends only on the fact, that any line can be made to coincide with any other line, that two lines do so coincide when they have two points in common, and further, that a line may be turned about any point in it without leaving the surface. But if instead of the plane we take a spherical surface, and instead of a line a great circle on the sphere, all these conditions are again satisfied.

The reasoning employed must therefore be fallacious, and the error lies in the words printed in italics; for these words contain an assumption which has not been proved. In fact they contain an axiom which completely replaces Euclid's Axiom XII., viz. it expresses that property of a plane which differentiates it from the sphere.

On the sphere it is, of course, not true that rotation is independent of translation, simply because every translation-sliding along a great circle-is a rotation about the poles of the great circle.

From this it might be said to follow that the calculus of quaternions must be wrong. But this again is not correct. The fact is that the celebrated author of this calculus had built it up with the full knowledge of the fundamental space properties in his mind, and making full use of them. Afterwards, on reasoning backwards, he got these space properties out of his formulæ, forgetting that they were exactly the facts with which he started. The process is, as far as logic is concerned, not very different from that practised by some alchemists, who pretended to make gold, and actually did produce gold out of their crucibles, but only as much as they had themselves put in.

The following considerations may help to clear up this point still further :-

Prof. Sylvester once conceived, in illustration of some points connected with our subject, an infinitely thin bookworm living in a surface, and consequently limited in its space conceptions to the geometry on such surface. In a similar manner we may imagine an intelligent being consisting merely of an eye occupying a fixed point in space, but capable of perceiving rays of light in every direction. For such a being space would have two dimensions only, but in this space it could conceive figures for which most of Euclid's definitions and all axioms with the exception of the twelfth, and therefore all propositions up to the twenty-sixth in the first book, would hold. Only the names point, line, angle, \&c., would stand for objects different to those which they represent to our mind. Nothing can put the vagueness of Euclid's definitions and the real nature of his axioms, viz. that they contain the real logical definitions of the geometrical entities, in a clearer light than the fact that it is possible to use these so-called definitions for objects quite different from those to which Euclid applied them.

To return to our imaginary being : let us suppose it capable of studying Euclid. A ray of ligbt, that is, a line, 
would appear to it as having no extension but only position, and would answer Euclid's definition of a point. Two such rays determine a plane, but to the eye this would have one dimension only, and it would lie evenly between its boundaries; calling the latter "points" it answers the description of lying evenly between its extreme points, and may be called a straight line, whilst the angle between the two rays would be the distance between the points. If two of these lines be drawn from the same point, we get as the inclination between them a rectilineal angle; this being to our mind the dihedral angle between two planes. If a line A B were made to revolve about its fixed end $\mathrm{A}$, the other point $\mathrm{B}$ would describe a circle; in our space a cone of revolution.

The following is a list of those definitions and axioms from Euclid with which we have here to deal. It will be seen that they hold, every word of them, for the figures above described as conceived by our eye-being. Only it must be remembered that a point for the eye-being is to our mind a line through the eye, and so for the line, \&c. The words in square brackets indicate what the figures are to our mind.

\section{DEFINITIONS}

I. A point [line through the eye] is that which has no parts or which bas no magnitude.

II. A line [conical surface with vertex in the eye] is length without breadth.

IV. A straight line [plane through the eye] is that which lies evenly between its extreme points [lines through the eye].

IX. A rectilineal angle [dihedral angle] is the inclination- of two straight lines [planes through the eye] to one another which meet together but are not in the same straight line [plane].

$\mathrm{X}$. When a straight line [plane] standing on another straight line [plane] makes the adjacent angles equal to one another, each of the angles is called a right angle [right dihedral angle].

$\mathrm{XV}$. A circle [cone of revolution with vertex at the eye is a figure contained by one line [surface] which is called the circumference, and is such that all straight lines [angles] drawn from a certain point within the figure to the circumference are equal to one another.

XVI. And this point [line] is called the centre of the circle [axis of the cone].

Axioms called Postulates in Euclid

I. Let it be granted that a straight line [plane through the eye] may be drawn from any one point [line through the eye] to any other point [plane determined by two lines through the eye].

1I. That a terminated straight line may be produced to any length in a straight line [plane through intersecting lines may be produced beyond these lines].

III. And that a circle may be described from any centre at any distance from that centre [a cone about any axis with any angle at the vertex].

\section{Axioms}

$\mathrm{X}$. Two straight lines cannot inclose a space [two planes through a point cannot inclose a space]

$X I$. All right [dihedral] angles are equal to one another.

Starting with the above definitions and axioms, the eyebeing would have no difficulty in mastering the constructions and theorems contained in the first propositions of the "Elements." Only in Proposition IV. a difficulty might occur. For it may perhaps prove to be impossible to make the two triangles coincident. In Euclid's triangles, namely, it may be necessary to take of one of the triangles the side opposite to the one originally given by taking it out of the plane and turning it over before it can be made to coincide with the other triangle. So perhaps our being would find out, if the two triangles [trihedral angles] were right- and left-handed, that it has to take of one of the triangles the opposite side, viz. that on the other side of itself [formed by the continuations of the rays], which then will answer the purpose. After this every other proposition would follow without difficulties till parallel lines were introduced, which might sorely puzzle our eye-being, and finally be dismissed as downright nonsense, parallel lines being absolutely inconceivable. And if Sir William Hamilton's proof of the proposition that the sum of the angles in a triangle equalled two right angles were given to it, it would grant the construction and every step as possible and correct, but it would "shake its head" about the conclusion included in the words printed above in italics. It might even consider Euclid a fit subject for a "Budget of Paradoxes." For it is difficult to imagine that this being without moving in space should be able to generalise and invent a geometry in a space of zero curvature.

If in any one of the first twenty-six propositions of Euclid the changes above indicated are made from our conceptions to those of the eye-being, we get a series of well-known fundamental propositions in solid geometry which when obtained in this manner do not require any further proof.

O. HENRICI

\section{THE SCIENTIFIC WORK OF THE "VEGA" EXPEDITION 1}

$\mathrm{THE}$ second volume of this work is as rich an addition to our knowledge of the far north as the previous one. It contains also not only the bare results of the observations of the scientific staff of the Vega, but also a series of elaborate papers connected with the various tupics which were within the circle of the researches of the expedition.

F. R. Kjellman contributes two more papers on the Arctic flora. In the first of these he deals with the phanerogamous flora of the island of St. Lawrence, situated under the 63rd parallel in the Behring Straits. This island has been represented in Middendorff's work as quite devoid of trees and shrubs, although Chamisso had seen on it large spaces covered with a Salix. M. Kjellman found, during his very short stay at the island, no less than 96 species of phanerogams, of which 53 are new for the island, the whole of the phanerogamous species known reaching thus II 3 (22 Monocotyledons, and 9I Dicotyledons). They are chiefly Gramineæ (I I species), Compositæ, and Ranunculaceæ (9 species each), Saxifragaceæ, Cruciferæ, and Caryophyllaceæ ( 8 species each); the Scrophulariaceæ, Salicineæ, and Cyperaceæ are represented by 7 species each. The flora is purely Arctic; I05 species being East Siberian, 79 West Siberian, and IoI West American. The island proves to have thus taken in species indifferently from the eastern and from the western continent. Having, however, a few genera more in common with Siberia than with America, and these genera having also a wider extension in Siberia, it would seem that the island stands in a somewhat closer connection with Asia than with America. It is worthy of notice that M. Kjellman found no endemic species; only the variety tomentosa of the Cineraria frigida, and Saxifraga neglecta, var. stolonifera, which show such variations from the typical forms as might lead them to be considered perhaps as separate species. Both are figured on plates that accompany the paper, as well as Saxifraga neglecta, var. congesta, from the land of the Chukches.-Another paper, by the same author, deals with the phanerogams of the "Western Esquimaux Land," that is of the northwestern extremity of North America, between Norton

I "Vega-Expeditionens Vetenskapliga SaktlageIser, bearbetade af cielta gare i resan och andra forskare, utgifna af A. E Nordenskjöld." Andra bandet, med 32 taflor. 